\title{
The Effect of Education on Nationalism and Ethnic Exclusionism: An International Comparison
}

\author{
Marcel Coenders and Peer Scheepers \\ Department of Sociology/ICS, University of Nijmegen
}

\begin{abstract}
In most studies on ethnic attitudes, a rather strong negative relationship has been found between educational attainment and positive ingroup attitudes (or negative outgroup attitudes). However, it is not well known to what extent this educational effect varies across different national contexts. This study investigated the effect of education on different dimensions of nationalism and ethnic exclusionism with the use of 1995 survey data gathered in 22 countries. Notions from socialization theory were used to test whether the educational effect varies according to the length of liberal-democratic tradition and the degree of religious heterogeneity within a country. Results indicate that educational attainment is strongly related to ethnic exclusionism as well as chauvinism, but not to patriotism. Moreover, the effect of education on ethnic exclusionism is smaller in recently established democracies. The hypothesis regarding stronger educational effects in societies with more religious heterogeneity was not supported.
\end{abstract}

KEY WORDS: nationalism, ethnic exclusionism, attitudes, education, international comparison

One of the most consistent findings in social research on ethnic attitudes is the negative association between educational attainment and ethnic prejudice: People with higher education are less prejudiced toward ethnic outgroups than are those with lower education. This relationship has been established in empirical research across time as well as in different countries (Fuchs, Gerhards, \& Roller, 1993; Schuman, Steeh, Bobo, \& Krysan, 1997; Smith, 1981, 1985; Taylor, Sheatsley, \& Greeley, 1978; Vogt, 1997). Although most studies focus solely on attitudes toward ethnic outgroups, there is also empirical evidence that people with higher education are less prone to ingroup favoritism than are people with lower education (Billiet, Carton, \& Huys, 1990; Eisinga \& Scheepers, 1989). In short, ethnocentrism - the combination of a favorable attitude toward the ethnic ingroup and an unfavorable attitude toward ethnic outgroups (Adorno, Frenkel-Brunswik,

0162-895X @ 2003 International Society of Political Psychology Published by Blackwell Publishing. Inc., 350 Main Street, Malden, MA 02148, USA, and 9600 Garsington Road, Oxford, OX4 2DQ 
Levinson, \& Sanford, 1950; LeVine \& Campbell, 1972; Sumner, 1906/1959)—is more commonly found among lower-educated strata.

Because of the relative scarcity of cross-nationally comparable survey data, it is not well known whether this effect of education is universal, or whether and to what extent it varies across countries. According to Weil (1985), the effect of education may vary systematically across countries. However, Weil's four-country study had severe shortcomings due to incomplete comparability in the applied data. In this study, we set out to improve on previous research - in particular Weil's study — by applying cross-nationally comparable measurements of ingroup and outgroup attitudes of the ethnic majority population in 22 countries. We label positive attitudes toward one's ingroup and country as nationalism, and negative attitudes toward ethnic minorities and immigrants as ethnic exclusionism. ${ }^{1}$

We investigated whether the effect of educational attainment on nationalism and ethnic exclusionism varies systematically across types of countries. In particular, we tested hypotheses that the educational effect varies across countries with the length of time a country has had a liberal-democratic regime form or the degree of religious heterogeneity within a country.

\section{Previous Empirical Research on the Effect of Education}

The negative relationship between educational attainment and (various measures of) ethnic intolerance has been established time and again, especially in studies of the white American population (Schuman et al., 1997; Vogt, 1997). In a series of articles, applying continuous survey research from 1942 onward, Sheatsley and various co-authors showed that white Americans with higher education are more supportive of racial integration (Greeley \& Sheatsley, 1971; Hyman \& Sheatsley, 1956, 1964; Taylor et al., 1978). Selznick and Steinberg (1969) and Martire and Clark (1982) found less anti-Semitism among people with higher education. Research in Western European countries also indicated that negative stereotypes toward ethnic minorities are less common among the higher educated (Billiet et al., 1990; Eisinga \& Scheepers, 1989; Wagner \& Zick, 1995; Winkler, 1999). Furthermore, support for disadvantageous treatment of ethnic minorities in the housing and labor market was found to be particularly present among people with lower education (Coenders \& Scheepers, 1998). Empirical studies have also shown effects of educational attainment in other realms (for an overview, see Hyman \& Wright, 1979) such as moral attitudes (Walzer, 1994; Wilcox, 1992) and political tolerance or support for civil liberties (Bobo \& Licari, 1989; Lipset, 1981; Stouffer, 1955).

\footnotetext{
${ }^{1}$ This conceptualization of nationalism does not incorporate political-ideological striving for an independent nation-state. Moreover, because we focus on the attitudes of members of the ethnic majority within each country, we do not distinguish between a positive attitude toward one's ethnic ingroup and a positive attitude toward one's country.
} 
Our study investigates the relationship between education and negative attitudes toward ethnic minorities and immigrants as well as positive attitudes toward the ethnic ingroup. The interrelation between unfavorable attitudes toward outgroups and favorable attitudes toward the ingroup is called ethnocentrism. Although the concept of ethnocentrism was introduced nearly a century ago by William Sumner (1906/1959) and adopted by Adorno et al. (1950) and others, most contemporary research focuses solely on attitudes toward ethnic outgroups, neglecting attitudes toward the ingroup. However, some studies have shown a negative relationship between education and positive attitudes toward the ethnic ingroup; that is, chauvinistic nationalistic feelings are less widespread among persons with higher education (Billiet et al., 1990; Eisinga \& Scheepers, 1989). In short, the dominant research finding has been that educational attainment is associated with increasing tolerance toward ethnic outgroups and decreasing feelings of ingroup superiority.

However, this effect of education is not universal. That is, the effect of education on interethnic attitudes and tolerance varies across contexts. First, the educational effect depends on the applied measure of ethnic tolerance. Second, there are some indications that the effect of education varies across countries.

With respect to the applied measurement, Hyman and Sheatsley (1956) found strong effects of education on approval of school integration and approval of integration of public transportation, but they found no differences between educational groups with respect to the approval of residential integration. ${ }^{2}$ Smith (1981) compared approval of the principle of school desegregation with willingness to send one's children to a school where a few, half, or most of the children are blacks. The liberalizing effect of education varied negatively with the proportion of blacks in the school. The same findings are reported by Schuman et al. (1997) in an overview study of trends in racial attitudes in the United States between the 1940 s and the 1990s. In addition, they found similar effects with respect to residential integration. ${ }^{3}$ They concluded that when the degree of integration proposed would make whites into a minority, highly educated respondents are no longer in the vanguard. Moreover, Schuman et al. reported that educational attainment is generally associated with stronger adherence to principles of non-discrimination and desegregation, but that this association tends to decrease or even disappear when implementation of these principles is involved (see Jackman, 1978; Jackman \& Muha, 1984).

Not only does the effect of education depend on the measure of ethnic intolerance, there is some evidence that the effect of education may vary across

\footnotetext{
${ }^{2}$ According to Hyman and Sheatsley, the lack of a bivariate relation between education and approval of neighborhood integration may be due to the effect of social and financial status, which illustrates the need for a multivariate analysis.

${ }^{3}$ There are (at least in the northern United States) small educational differences in the willingness to move when some blacks reside in one's neighborhood, but the effect of education disappears when the survey question refers to a large proportion of black residents.
} 
countries. On the basis of a study of anti-Semitism in four countries, Weil (1985) concluded that, in general, education had the largest effect in the United States, smaller effects in West Germany and France, and the smallest effect in Austria.

A major drawback of Weil's study is the incomplete comparability of his data. Because of the lack of cross-nationally comparable data, he was forced to apply items that had different item formulations and answer categories across countries, and were gathered in different years in different countries. Therefore, as Weil acknowledged, his results are more suggestive than conclusive.

With the cross-national survey data gathered by the International Social Survey Program (ISSP), it is now possible to investigate the effect of education on interethnic attitudes more thoroughly and systematically. The 1995 ISSP data set "Aspects of National Identity" has several advantages. First, equivalent question wordings and answer categories are applied in each country. Second, data are gathered in a large heterogeneous set of countries-covering Western European countries, former socialist countries in Eastern Europe and Russia, and traditional immigration countries such as the United States and Australia-allowing a systematic investigation of the liberalizing effects of education.

\section{Theoretical Interpretations of the Educational Effect}

Although numerous studies report an overall negative effect of education on ingroup favoritism and/or outgroup prejudice, it is much less clear why education has such an effect. Various interpretations have been offered, but few investigations have empirically tested the factors causing the negative effect of education on ethnocentrism.

In this study, we focus on socialization theory as a possible explanation of the educational effect. Central to socialization theory is the thesis that educational institutions transmit norms, values, and models of behavior deemed to be appropriate in a given society. The negative association between education and nationalism or ethnic exclusionism is particularly due to the dissemination of democratic value orientations in the educational system (Selznick \& Steinberg, 1969).

In contemporary research, most theoretical interpretations regarding the relation between education and interethnic attitudes stress the cognitive component of these attitudes. In this cognitive approach, it is emphasized that prejudiced beliefs are intellectually unenlightened beliefs (Selznick \& Steinberg, 1969; Weil, 1985). Ethnic stereotypes - whether positive stereotypes toward the ingroup or negative stereotypes toward outgroups-are simplifications of social reality; they are generalizations that are improperly applied to all members of an ethnic group. Likewise, xenophobic beliefs in which immigrants and foreigners are viewed as the (primary) cause of societal problems reflect a simplified view of social reality. Individuals with a primitive cognitive style assign blame to ethnic outgroups and search for scapegoats because they fail to comprehend impersonal and abstract causes (Selznick \& Steinberg, 1969). Nevertheless, although many stereotype 
attributions are crude and simple, they are to a certain extent inevitable in order to deal with the complexities of daily social life. The question then becomes why highly educated people reject such prejudiced beliefs and antagonistic attitudes that arise from these beliefs. According to the cognitive approach, the differences in prejudice between educational groups can be interpreted in terms of central processes within the educational system: the transfer of knowledge and information; the development of cognitive capacities; and, finally, the transfer of norms, values, and modes of behavior, which is the central thesis in the above-mentioned socialization theory (see de Witte, 1999).

Regarding the first of these central processes, education is characterized as a learning process through which people acquire knowledge and information. Basically, this relates to the well-known "ignorance causes prejudice" thesis (Stephan \& Stephan, 1984). A higher level of education increases insight into the complexity and multicausality of society and of individual behavior, refuting simplifications inherent in ethnic stereotypes. In addition, education broadens one's social perspective: It increases the knowledge and understanding of different norms and values other than those common in one's own social group. Education therefore raises awareness of the subjective and particularistic character of individual beliefs (Gabennesch, 1972; Roof, 1974). Hyman, Wright, and Reed (1975), in their comprehensive review of American data, concluded that education indeed increases knowledge, deepens receptivity to further knowledge, and stimulates active seeking for new information long after people finish their formal schooling. Furthermore, Stephan and Stephan (1984) showed that cultural knowledge (knowledge of the roles, norms, and values) of an ethnic outgroup is strongly correlated with positive attitudes toward that outgroup.

Second, the relation between educational attainment and interethnic attitudes is interpreted in term of cognitive capacities and/or habits. That is, education may increase the cognitive abilities necessary for a sophisticated analysis of problems in order to counterbalance the rigid simplifications inherent in most positive ingroup and negative outgroup attitudes. Although this interpretation is widespread, only a small number of studies have used direct measures of cognitive abilities. For instance, Wagner and Schönbach (1984) found that their measure of cognitive complexity was an important mediator in the link between educational status and ethnic prejudice. In a study on the related topic of political tolerance, Bobo and Licari (1989) found a strong effect of their measure of cognitive sophistication. ${ }^{4}$

Whereas the aforementioned theoretical approaches stress the cognitive component of prejudice, other theories focus on personality needs as the cause of prejudice. The best known example of this personality development approach is

\footnotetext{
${ }^{4}$ Studies show a wide variety of conceptualizations and measurements of cognitive capacities-for example, associative flexibility, cognitive complexity or flexibility (Wagner \& Schönbach, 1984), and cognitive sophistication (Bobo \& Licari, 1989).
} 
the theory of the authoritarian personality (Adorno et al., 1950). Previous studies have shown strong empirical interrelations between ethnic prejudice and authoritarianism, as well as between lower educational attainment and higher levels of authoritarianism (Adorno et al., 1950; Scheepers, Felling, \& Peters, 1990). In addition, the interrelation between education and prejudice has been interpreted in terms of self-esteem (Wagner \& Schönbach, 1984). It is assumed that persons with higher education, and in general higher social strata, have higher self-esteem and are therefore less inclined to enhance their social identity by perceiving their ingroup as superior to outgroups (Tajfel, 1981, 1982).

Next to the cognitive approach and the personality development approach, the relationship between educational attainment and nationalism or ethnic exclusionism can also be interpreted by realistic group conflict theory (LeVine \& Campbell, 1972). Central in this theory is the proposition that competition for scarce resources between social groups (e.g., ethnic groups) is the catalyst of antagonistic attitudes: Intergroup competition leads to more ingroup solidarity and to more outgroup hostility (Bobo, 1988; Olzak \& Nagel, 1986; Sherif \& Sherif, 1979). In this view, ethnic groups are mutual competitors, because they have conflicting claims over status, power, privilege, and other scarce resources, along with expectations and subjective judgments about the "proper" distribution of such scarce resources (Blumer, 1958; Coser, 1956). According to Blalock (1967), actual competition is reflected in perceptions of competition-that is, the subjectively perceived socioeconomic threat that ethnic minorities pose to the social position of the dominant ethnic group. However, the extent to which dominant ethnic group members experience threat from ethnic minorities may depend on their personal situation. In particular, those social categories that hold social positions similar to those of the ethnic minorities will have to make extra effort to compete with ethnic minorities in the labor and housing markets. Because ethnic immigrants and minorities are in general overrepresented in the lower strata of society (Kiehl \& Werner, 1998), it is to be expected that nationalism and ethnic exclusionism are strongly prevalent among people of lower education levels, lower social classes, and lower income groups. Because education, social class, and income are strongly interrelated, as shown by status-attainment models, it is necessary to estimate the effect of educational attainment in a multivariate analysis, controlling for the effects of social class position and income level.

Some authors doubt whether there really is a true effect of education, or whether the effect is (to some extent) an empirical artifact. For instance, the effect of education may be overestimated because respondents with lower education tend to answer in the affirmative to the (ethnocentric) items offered (Jackman, 1973). Schönbach, Gollwitzer, Stiepel, and Wagner (1981), however, found no support for this "acquiescent response bias." Moreover, the effect of education may be overestimated because respondents with higher education are more predisposed to give socially desirable answers. To test this latter proposition, Wagner and Zick 
(1995) conducted an experiment with a bogus-pipeline measurement procedure, in which responses are relatively free of response tendencies and strategies of positive self-presentation. As expected, respondents expressed more negative outgroup attitudes when their attitudes were measured by the bogus-pipeline procedure than by a paper-and-pencil method. However, contrary to expectations, the difference between respondents with higher and lower education was even stronger in the bogus-pipeline experimental group. This finding indicates that under conditions in which the tendency to give socially desirable answers is reduced, the differences between educational groups may actually increase.

We now return to the question of whether the effect of education on nationalism and ethnic exclusionism varies across countries. Most of the aforementioned theories on the relation between education and ethnic attitudes do not incorporate any explanations of varying effects of educational attainment across countries. In a strict sense, psychodynamic theories that focus on personality needs, such as the theory of the authoritarian personality (Adorno et al., 1950), pose no crosscultural variation (see Weil, 1985). Other theoretical propositions are difficult to test by means of cross-sectional survey data. For instance, testing the notions that educational systems transfer knowledge and information or support the development of cognitive abilities would ideally require a detailed examination of the content of educational curricula and teaching practices across countries. Alternatively, socialization theory can be applied to derive testable hypotheses regarding cross-national variations in the educational effect. The aforementioned notions of realistic group conflict theory point out that such hypotheses should be tested in multivariate analyses, controlling for the effects of social class position and income level.

\section{Socialization Theory}

Central to socialization theory is the thesis that students are exposed to values, norms, and modes of behavior transmitted by the educational system. That is, education brings people into contact with the official norms and values of the society. According to Selznick and Steinberg (1969), the formal educational system is the main social institution for the transmission and elaboration of what they designate as the "official" culture. This official or ideal culture, which contains society's ideal norms, is distinguished from the "unofficial" or "common" culture. Selznick and Steinberg viewed the official culture of the United States as an enlightened and unprejudiced culture organized around scientific and democratic values. Conversely, they viewed the historically more archaic common culture in the United States as a prejudiced culture, characterized by pre-scientific, pre-democratic, and pre-humanitarian values. Thus, the longer individuals attend the educational system, the more they are exposed to scientific and democratic values. Because most prejudiced beliefs are, as Selznick and Steinberg argued, incongruent with 
these values, adherence to scientific and democratic values and ideals can countervail the (cognitively unenlightened) prejudiced beliefs. ${ }^{5}$

Selznick and Steinberg's analysis of the relation between education and (antiSemitic) prejudice was confined to the United States. They argued that in such a society, with its democratic political order and its technologically based economy, the ideal norms of the official culture are derived from democratic and scientific values. Weil (1985) generalized their thesis by stating that the values that are transmitted by a country's educational system reflect the official or political culture of that country, which in turn is determined by the existing regime form. That is, in countries with a liberal, democratic regime, the official or political culture encompasses democratic values and ideals, which are promulgated by the educational system. Accordingly, the negative association between education and nationalism or ethnic exclusionism is due to the dissemination of democratic value orientations in educational institutions. However, the values transmitted by the educational system reflect the dominant political culture; hence, one would expect that the effect of education is smaller in countries with a less democratic regime or a less longstanding democratic tradition.

The ISSP data set offers a unique opportunity to test these propositions. The inhabitants of Eastern Europe and Russia have only recently witnessed the transformation from a socialist one-party political power to a democratic political regime form. Most of the adult population in Eastern Europe and Russia attended educational institutions in times of a non-democratic government. Therefore, we expect that the differences between educational groups in nationalism and ethnic exclusionism are smaller in these former socialist countries. Our first hypothesis therefore asserts that the effect of education on nationalism and ethnic exclusionism depends on the political regime form of the country: The effect of education is smaller in recently established democracies (Hypothesis 1a).

Weil furthermore assumed a time lag between a change in political regime form and the ability of the educational system to socialize students into the new official political culture. Therefore, the length of time a country has had a liberaldemocratic regime form determines the extent to which the population is socialized in democratic ideals and values. Consequently, we expect that the effect of education is stronger in prolonged democracies than in countries where the liberaldemocratic tradition has been interrupted, such as Italy, Germany, Austria, Spain, and Japan, which had non-democratic regime forms during the 1940s or (in the case of Spain) for many years thereafter. Thus, the effect of education on nationalism and ethnic exclusionism depends on the length of time a country has had a

\footnotetext{
${ }^{5}$ According to Selznick and Steinberg, prejudiced beliefs are cognitively simplistic beliefs and thus incongruent with the scientific rules of evidence and inference as promulgated by the educational institutions. This notion corresponds with the view that educational differences in prejudice are due to differences in cognitive abilities and habits between educational groups.
} 
liberal-democratic regime form: The effect of education is the strongest in prolonged democracies, less strong in interrupted democracies, and the smallest in recently established democracies (Hypothesis $1 b$ ).

In addition, Weil hypothesized that the political culture, as transmitted by the educational system, is also affected by the degree of cultural pluralism. On the basis of studies of conflict resolution in plural societies (e.g., Lijphart, 1977), Weil stated that in a plural society, in order to avoid overt conflict between population segments, the political elites must take the lead in promoting peaceful accommodation among the different groups. Because the political culture is transmitted through the educational system, it is assumed that in a more plural society, educational institutions are more likely to attempt to teach and promulgate tolerant values and attitudes. We test this notion by investigating to what extent the effect of education varies with the degree of religious heterogeneity of a country. Our hypothesis therefore asserts that the effect of education depends on the degree of religious heterogeneity of a country: The effect of education is stronger in societies with more religious heterogeneity (Hypothesis 2 ).

\section{Data and Measurements}

Data were derived from the 1995 module of the ISSP. The ISSP, founded in 1983 with the goal of achieving more cross-national comparability in attitudinal research, conducts annual cross-national survey research in a growing number of countries. The 1995 Aspects of National Identity survey was conducted among probability-based nationwide samples of adults in 23 countries. The questionnaire module was jointly developed by the ISSP members, with each question formulated to be as culturally neutral as possible, and the module was pretested in various countries.

In our analyses we apply data from 22 countries, excluding the Philippines (the sole non-industrial country in the data set) for reasons of comparability. Data for Germany are analyzed separately for the territories of the (old) Federal Republic of Germany (BRD) and the former German Democratic Republic (DDR) because of the immense differences in political and economic developments since the Second World War. Among the 22 countries there is wide variety with respect to region, ethnic and religious heterogeneity, and immigration history, as well as the length of time a country has had a liberal-democratic regime form. With regard to the latter characteristic, we distinguished three groups of countries: countries with a longstanding tradition of democratic government, countries where the liberal-democratic tradition has been interrupted by a non-democratic regime before or (as in Spain) after 1945, and the former socialist countries in Europe and Russia that only recently transformed toward political democracy. Furthermore, we grouped the countries by degree of religious heterogeneity. On the basis of the religious denomination of all respondents within each country sample, we 
calculated an index of religious diversity ${ }^{6}$ (Agresti \& Agresti, 1977). In this manner, we distinguished between relatively homogeneous countries, moderately heterogeneous countries, and relatively heterogeneous countries. Appendix A shows the length of liberal-democratic tradition and the degree of religious heterogeneity for each country.

When studying attitudes toward ethnic minorities and immigrants, one should distinguish between attitudes of the ethnic majority group and those of ethnic minority groups. Here, we restrict our analyses to the attitudes of the ethnic majority group in each country. ${ }^{7}$ In Appendix B, the selection of respondents from the ethnic majority group is explicated, along with the sample sizes for each country. To avoid a small effective sample size, we applied missing mean substitution (within each country) for the indicators of nationalism and ethnic exclusionism.

\section{Dependent Variables: Dimensions of Nationalism and Ethnic Exclusionism}

In a previous article (Coenders \& Scheepers, 1999), we applied the ISSP 1995 data to investigate whether there are several dimensions of nationalism and ethnic exclusionism. In accordance with previous research on the multidimensionality of attitudes toward one's own people and country (Bar-Tal \& Staub, 1997; Blank \& Schmidt, 1993; Kosterman \& Feshbach, 1989), our results indicated that two dimensions of nationalism can be distinguished: chauvinism and patriotism. Chauvinism can be described as the view that one's own ethnic ingroup and country are unique and superior. This downward comparison of other ethnic groups and countries is combined with a blind, uncritical attachment to one's own group and country. Patriotism, the love for and pride in one's people and country, refers to an attachment based on critical understanding.

The distinction between chauvinism and patriotism is in line with the notions of Adorno et al. (1950). They labelled the combination of feelings of superiority and a blind attachment to the country and the national group as "pseudopatriotism" (as opposed to "genuine patriotism"), defined as a "blind attachment to certain national cultural values, uncritical conformity with the prevailing group ways, and rejection of other nations as out-groups" (p. 107). More recently, Staub

${ }^{6}$ The index of diversity was calculated as:

$$
\text { heterogeneity }=\frac{1-\sum_{j=1}^{N_{j}}\left(\frac{f_{j}}{N}\right)^{2}}{1-\frac{1}{N_{j}}}
$$

with $\mathrm{N}=$ total frequency; $\mathrm{f}_{\mathrm{j}}=$ frequency of category $\mathrm{j} ; \mathrm{N}_{\mathrm{j}}=$ number of categories. The index was adjusted for the total number of denominations that were distinguished in the questionnaire, as is displayed by the denominator of the equation.

${ }^{7}$ We do not elaborate on the attitudes of ethnic minority groups because of the overall small number of respondents from these ethnic groups in national representative samples. 
(1997) and Schatz, Staub, and Lavine (1999) suggested a more refined distinction between nationalism, blind patriotism, and constructive patriotism. Nationalism was defined as feelings of national superiority and support for national dominance. Blind patriotism was defined as a rigid and inflexible attachment to the country characterized by unquestioning positive evaluation, staunch allegiance, and intolerance of criticism. Constructive patriotism, on the other hand, was defined as an attachment to the country characterized by support for questioning and criticism of current group practices that are intended to result in positive change (Staub, 1997). Both blind and constructive patriotism are considered distinct from nationalism, since in their conceptualisation, nationalism refers to an intergroup comparison, whereas both blind and constructive patriotism do not. However, nationalism and blind patriotism were strongly interrelated $(\mathrm{r}=.65)$ (Schatz et al., 1999). In our study, we applied previously gathered secondary data, that did not exactly match the distinction between nationalism, blind and constructive patriotism as proposed by Staub and Schatz et al. Our conceptualisation and measurement of chauvinism relates more to the aforementioned concepts of nationalism and blind patriotism, whereas our concept of patriotism more closely relates to the concept of constructive patriotism.

Next, various types of ethnic exclusionism could be distinguished, reflecting attitudes toward different types of ethnic outgroups: resident ethnic outgroup members (ethnic minorities), immigrants, and political refugees. ${ }^{8}$ Ethnic majority members' attitudes toward ethnic minorities depend on their subjective definitions of the ingroup and outgroups, and on their subjective perceptions of the typical characteristics of "true" ingroup members. When individuals from the ethnic majority group hold a strong view that certain characteristics (such as being a native-born or long-term resident in their country) are very important requirements for being a "true" member of their ingroup, they are more likely to be restrictive in their notion of the ingroup and are more likely to exclude members from ethnic minorities. Attitudes toward immigrants and political refugees are a function of the willingness of the ethnic majority to close the national borders to ethnic newcomers.

Eleven items, as shown in Table 1, were selected from a larger pool of items as indicators for the aforementioned dimensions of nationalism and ethnic exclusionism. ${ }^{9}$ First, chauvinism is measured by items referring to the superiority of one's own country and its residents, as well as an item that refers to a blind, uncritical attachment to one's own country. Next, items referring to patriotism measure pride in collective goods of the country-its democracy, political influence, and economic achievements. Another set of items refers to exclusion of

\footnotetext{
${ }^{8}$ Structural equations modeling applying the LISREL program showed that items referring to exclusion of immigrants and to exclusion of political refugees did not refer to the same latent variable, because parameter estimates of such a model showed anomalies (Coenders \& Scheepers, 1999).

${ }^{9}$ On the basis of the results of preliminary analyses, these items were judged to be the most appropriate ones for the construction of an internationally comparable measurement instrument.
} 
Table 1. Indicators of Dimensions of Nationalism and Ethnic Exclusionism

Nationalism: Chauvinism

I would rather be a citizen of [country] than of any other country in the world. (strongly agree-strongly disagree)

The world would be a better place if people from other countries were more like the [nationality]. (strongly agree-strongly disagree)

People should support their country even if the country is in the wrong. (strongly agree-strongly disagree)

Nationalism: Patriotism

How proud are you of [country] in each of the following? (very proud, somewhat proud, not very proud, not proud at all)

The way democracy works

Its political influence in the world

[Country's] economic achievements

Ethnic exclusionism: Exclusion of immigrants

Do you think the number of immigrants to [country] nowadays should be . . (increased a lot, increased a little, remain the same as it is, reduced a little, reduced a lot)

Ethnic exclusionism: Exclusion of political refugees

Refugees who have suffered political repression in their own country should be allowed to stay in [country]. (strongly agree-strongly disagree)

Ethnic exclusionism: Exclusion from ingroup membership

Some people say the following things are important for being truly _ [e.g., British].

Others say they are not important. How important do you think each of the following is? (very

important, fairly important, not very important, not important at all)

To have been born in [country]

To have lived in [country] for most of one's life

To be able to speak [national language(s)]

Note. Brackets indicate country-specific question wording.

immigrants and political refugees, measuring the respondent's inclination to close the national borders to ethnic newcomers. Finally, exclusion from ingroup membership is measured by items referring to the importance of specific conditions for being a true member of the national community, and consequently, the degree to which members from ethnic outgroups who do not share these conditions are excluded.

To construct our measurement instrument, we used structural equations modeling with the LISREL program (Jöreskog \& Sörbom, 1993a, 1993b). Taking into account the ordinal scale scores of the items, we analyzed the matrix of polychoric correlations with the generally weighted least-squares method with a correct weight matrix. The scale indeterminacy of latent variables was eliminated by giving the latent variable the scale of one of the observed variables (i.e., fixing a factor loading to a value of 1). As illustrated in Figure 1, the observed variables 
are assumed to be unidimensional, referring to only one theoretical variable. Furthermore, the latent variables are allowed to covariate, whereas measurement errors of the observed variables are assumed to be uncorrelated with each other.

A rather crucial question in international comparative survey research concerns the comparability of the measurement instrument. To investigate the extent to which the aforementioned indicators of nationalism and ethnic exclusionism are cross-nationally comparable, we conducted multisample analysis (Jöreskog \& Sörbom, 1993b). Bollen (1989, p. 356) distinguished between two dimensions of model comparability: comparability in model form and comparability in parameter values. Table 2 shows the goodness-of-fit statistics of four models, starting with a model with only invariant model form, followed by three models with an increasing number of cross-nationally invariant model parameters.

In model 1 , the form of the measurement model as illustrated in Figure 1 is invariant across countries. That is, the parameter matrices $\left(\Lambda_{x}, \Phi\right.$, and $\left.\Theta_{\delta}\right)$ of the measurement models in the different countries have the same dimensions and the same pattern of fixed and freed elements. Consequently, it is assumed that an item is an indicator of the same theoretical construct in the different countries. As shown in Table 2, the $\chi^{2}$ test statistic of this model is significantly too large,

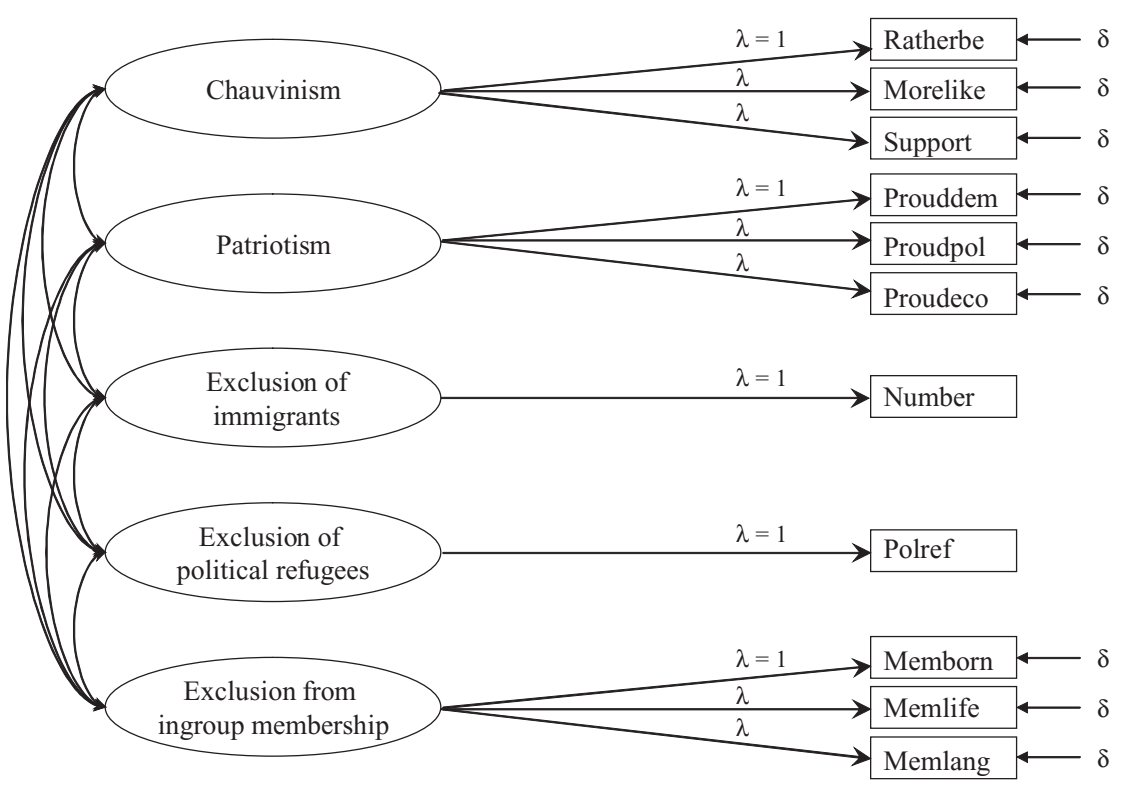

Figure 1. Measurement model for dimensions of nationalism and ethnic exclusionism. 
Table 2. Invariance in Measurement Models (23 samples; $N=24,778$ )

\begin{tabular}{llccccccccc}
\hline Model & \multicolumn{1}{c}{ Invariance in } & \multicolumn{1}{c}{$\chi^{2}$} & $\mathrm{df}$ & $\chi^{2} / \mathrm{df}$ & RMSEA & St. RMR & GFI & CFI & NFI & ECVI \\
\hline 1 & Model form & 2632.81 & 828 & 3.18 & 0.045 & 0.038 & 0.990 & 0.955 & 0.936 & 0.162 \\
2 & +factor loadings & 3241.48 & 960 & 3.38 & 0.047 & 0.042 & 0.988 & 0.942 & 0.921 & 0.176 \\
3 & +factor covariances & 5294.72 & 1180 & 4.49 & 0.057 & 0.047 & 0.985 & 0.896 & 0.871 & 0.241 \\
4 & +factor variances & 5816.92 & 1290 & 4.51 & 0.057 & 0.050 & 0.980 & 0.886 & 0.858 & 0.253 \\
\hline
\end{tabular}

${ }^{\text {a }}$ Standardized root mean square residual.

indicating a non-perfect fit. ${ }^{10}$ However, the root mean square error of approximation (RMSEA) is less than .05, which, according to Browne and Cudeck (1992), indicates a close fit of the model in relation to the degrees of freedom. In addition, the high values of goodness-of-fit index (GFI), comparative fit index (CFI), and normed fit index (NFI) suggest that model 1 has an acceptable fit. This finding implies that the invariance in model form is rather high. Therefore, one can conclude that in each country, the same indicator refers to the same theoretical concept.

The second model in Table 2 assumes not only an invariant model form, but also invariant relationships between indicators and theoretical variables - that is, invariant factor loadings across countries. In this model, there are no crossnational differences with respect to the (relative) degree to which indicators refer to a theoretical variable. ${ }^{11}$ Although the $\chi^{2}$ statistic for this restricted model shows a significantly worse fit compared to model 1 , the overall goodness-of-fit statistics GFI, CFI, and NFI are still rather high (0.988, 0.942, and 0.921, respectively). In addition, these fit statistics show only a minor drop compared to model 1. Moreover, the RMSEA is 0.047 , indicating a close fit of the model in relation to the degrees of freedom. In other words, the assumption that factor loadings are invariant in all 23 samples inevitably leads to a worse fit, but the loss of fit associated with this simplification seems to be acceptable. It is therefore more plausible that the same latent variables are being tapped in the different countries (Williams \& Thomson, 1986).

Building on the previous model, in model 3 the covariances between the latent variables are assumed to be cross-nationally invariant. As can be seen in

${ }^{10}$ Jöreskog and Sörbom (1993a, p. 122) suggested that in practice it is more useful to regard the $\chi^{2}$ statistic as a measure of fit rather than as a formal test statistic, because the $\chi^{2}$ test of the model against the alternative model that the covariance matrix of the observed variables is unconstrained is only justified if all model assumptions are satisfied, if the sample size is sufficiently large, and if the model holds exactly in the population.

${ }^{11}$ Because only ratios of factor loadings are identified - and not factor loadings themselves-the model assumes invariance of factor-loading ratios across countries. Invariance of all factor loadings across countries is not a testable assumption; however, if the assumption of invariant factor-loading ratios is justified, then it is probably safe to assume invariance of the factor loadings themselves (see Bielby, 1986). 
Table 2, the loss of fit associated with this even more simplified assumption is large: CFI and NFI drop from 0.942 and 0.921 to 0.896 and 0.871 , respectively. Likewise, the values of RMSEA and the expected value of the cross-validation index (ECVI) indicate a much smaller goodness of fit compared to model 2. To take the test of invariance of model parameters one step further, model 4 in Table 2 assumes not only invariant factor loadings and factor covariances, but also invariant factor variances. Not surprisingly, the fit of this most restrictive model is even less acceptable compared to model 3. In sum, whereas the first two models show a high and acceptable goodness of fit -indicating that the assumptions of invariance in model form and factor loadings can be justified - the considerably worse fit of models 3 and 4 shows that there are cross-national differences in associations between the latent variables. In other words, the applied items together form a cross-nationally comparable measurement instrument (i.e., with invariant factor loadings) for the dimensions of nationalism and ethnic exclusionism.

Applying the model with invariant factor loadings, the polychoric correlations between the dimensions of nationalism and ethnic exclusionism were estimated for each country. For a detailed discussion of these nationally specific associations between (dimensions of) nationalism and ethnic exclusionism, we refer to our previous study (Coenders \& Scheepers, 1999). Here we only mention some of the most striking results. First, in general, chauvinism is positively related to ethnic exclusionism. (Only in a few samples, for some of the dimensions of ethnic exclusionism, is the relationship not significant.) Second, chauvinism is more strongly related to ethnic exclusionism than is patriotism. This applies for each country and each dimension of ethnic exclusionism. This consistent finding corresponds to the conceptual distinction between chauvinism as a blind, uncritical national attachment combined with feelings of national superiority, and patriotism as a less extreme national attachment. Third, in most countries, patriotism is not significantly related to exclusion of immigrants or political refugees. Moreover, in five countries, patriotism is associated with less exclusion of immigrants (i.e., in Sweden, Hungary, Italy, the Czech Republic, and Canada) and with less exclusion of political refugees (i.e., in Norway, and again in Sweden, Hungary, Italy, and the Czech Republic). This finding illustrates that the notion of ethnocentrism (the combination of positive ingroup attitudes and negative outgroup attitudes) is too simplified. That is, a positive ingroup attitude - as expressed by a high degree of patriotism - does not necessarily imply outgroup hostility. Finally, in only three samples did we find a positive relation between patriotism and exclusion of immigrants or refugees: West Germany, East Germany, and Japan. ${ }^{12}$ Presumably, this striking finding is related to the special historical context in these nations, in which debates about national identity, pride, and patriotism may be

${ }^{12}$ Patriotism was also positively related to exclusion of political refugees in Bulgaria, but the relationship between patriotism and exclusion of immigrants was not significantly negative, so that the results for Bulgaria are ambiguous in this respect. 
strongly affected by national experiences before and during the Second World War. The troublesome relation of the nations with their collective past may have affected the connotation of patriotism in these countries.

\section{Independent Variables}

Educational attainment was measured by means of the international educational classification scheme of the ISSP. We collapsed the original seven categories into four categories: lower educational level, incomplete secondary educational level, completed secondary educational level, and higher educational level. ${ }^{13}$

To indicate respondents' social position, we combined several variables. First, we used a variable that indicates whether respondents are currently employed. Those who were not employed were further categorized as unemployed, students, retired persons, persons working in the household, and a miscellaneous category of other social positions (also including employees whose occupation could not be classified). Second, for those respondents currently employed, we recoded the available occupational classification codes into the nominal class typology of Erikson, Goldthorpe, and Portocarero (1979). Most ISSP members have applied the International Standard Classification of Occupations (ISCO) of the International Labor Office of the United Nations, either the 1968 revision or the 1988 revision (International Labor Office, 1969, 1990). ${ }^{14}$ To derive the EGP categories from ISCO68 and ISCO88, we followed the procedures of and standard modules generated by Ganzeboom, Luijkx, and Treiman (1989) and Ganzeboom and Treiman (1996). ${ }^{15}$ For five countries-Italy, the Netherlands, Japan, Great Britain, and Sweden - only a nationally specific occupational classification was available. We recoded these classifications into EGP classifications by hand, following the

${ }^{13}$ The lowest category of the seven-category ISSP classification refers to respondents with no educational qualifications as well as those still at school. Another variable indicates whether respondents are students. To achieve a better ordinal measure of educational level, we excluded respondents from our analyses if they were students and fell into the lowest category of the ISSP educational classification $(n=50)$.

${ }^{14}$ The 1995 ISSP data set (version May 1988) contains some errors concerning the variable with the ISCO-codes. That is, in contrast to the variable label, the specific variable does not contain the ISCO classification in the Czech and Slovak republics. We contacted the original investigators and found that for these countries the variable refers to a country-specific occupational classification. Therefore, the original investigators in the Czech and Slovak republics supplied us with, respectively, a new data file containing the ISCO-1988 variable and a recode scheme to recode the country-specific codes into ISCO-1988. Both files may be obtained from the first author.

15 To construct more appropriate EGP categories, we enhanced the occupational classification by adding information on employment status and supervisory status. That is, we applied three additional variables of the ISSP data set: a variable that indicates whether respondents are self-employed (available for each country); a variable that indicates the number of employees of self-employed persons (available for 15 countries), and a variable that indicates whether respondents supervise others at work (not available for the United States). 
aforementioned procedures. ${ }^{16}$ To avoid small class frequencies, we combined several class categories, resulting in a six-category nominal class classification: higher controllers, lower controllers, routine non-manual workers, self-employed (with or without employees), manual supervisors and skilled manual workers, and semi-unskilled manual workers. ${ }^{17}$

As a measure of economic position, we used household income. To achieve a cross-nationally comparable measure, we standardized this variable within each country. ${ }^{18}$ Furthermore, to avoid a small effective sample size, we substituted missing data by the country mean.

Finally, we included sex, age, religious denomination, and church attendance as control variables in the analysis. Because the various samples contained different age limits, we applied a common age limit for all samples, including only respondents between 18 and 75 years of age in the analyses. We distinguished 12 birth cohorts in order to explore possible nonlinear age effects. For the construction of the religious denomination variable, we subsumed small or country-specific denominations into broader denominational categories. We distinguished between Catholic, Orthodox, and Protestant denominations; non-religious persons; and finally, a category consisting of non-Christian denominations and non-valid answers (such as non-classifiable denominations, refusals, and other missing answers). Church attendance was measured by four categories, ranging from never going to church to attending nearly once a week or more. ${ }^{19}$

\section{Method}

To investigate the relationship between the aforementioned individual characteristics and nationalism and ethnic exclusionism, we applied multiple regression analyses. In these analyses, we computed the score for each dimension of nationalism and ethnic exclusionism by applying the average sum of scores of the specific indicators. Data were weighted to correct for nationally specific sample characteristics (Zentralarchiv, 1998). The total number of valid responses in the 23 national samples-from 22 countries, with East and West Germany treated as separate samples-is 24,247 . To achieve equal sample size for each sample, we reweighted the data to sample sizes of 1,000 (total $N=23,000$ ).

\footnotetext{
${ }^{16}$ The EGP classifications for Italy, the Netherlands, Japan, and Great Britain should be regarded with some caution because the original occupational categories were not very specific.

${ }^{17}$ In Italy, no distinction could be made between skilled and semi-unskilled manual workers.

${ }^{18}$ To distinguish between single-person households and other households with the same household income, we divided the household income by 2 for married or cohabiting respondents. In Russia, the variable refers to income per family member, and therefore we corrected the Russian data for household size.

${ }^{19}$ In three countries, a category "not applicable: no (Christian) religion" was applied. We subsumed these respondents into the category of non-churchgoers.
} 
All nominal variables as well as educational attainment and age were dummified. That is, the original variable was broken down into as many variables as it contained categories, minus one that served as a reference category.

To correct for country-specific effects, we included country as a dummy variable in the analyses, with one country as reference category. In this manner, we achieved more accurate estimates of the effects of individual characteristics ${ }^{20}$ To test whether the educational effect differs across countries according to liberaldemocratic tradition or degree of religious heterogeneity, we included interactions for education and liberal-democratic tradition, as well as for education and religious heterogeneity.

\section{Results}

Table 3 shows the results of a multivariate regression analysis in all countries simultaneously. For each of the five dependent variables, the unstandardized regression parameters are displayed. There are considerable differences between educational groups for four of the five dependent variables. When all the variables displayed in Table 3 are controlled for, respondents with lower education are more chauvinistic than those with higher education. Those with lower education are also more likely to exclude ethnic outgroups on all dimensions of ethnic exclusionism, although the sizes of the differences vary. Clearly, educational attainment is strongly related to chauvinism and ethnic exclusionism. In contrast, there are only minor differences between educational groups regarding the degree of patriotism. Only respondents with the lowest educational attainment level are significantly more patriotic than those with the highest education. Again, this confirms our previous finding that there is a substantial difference between a positive orientation toward the ingroup and one's own country, characterized by feelings of superiority and a blind, uncritical ingroup attachment (i.e., chauvinism), and feelings of pride in specific achievements of one's own country (i.e., patriotism).

There are also considerable differences in chauvinism and ethnic exclusionism between respondents with different social positions. In general, relative to the highest social class, lower social classes display a higher degree of chauvinism and ethnic exclusionism. This finding supports the notions of realistic group conflict theory. Relative to the reference category of higher controllers, the selfemployed workers and the manual supervisors/skilled manual workers score significantly higher on chauvinism and ethnic exclusionism. This is also the case for semi-unskilled manual workers as well as for those who are unemployed, with the exception that the difference between these groups and higher controllers is not significant for the degree of exclusion of political refugees. Furthermore, the routine non-manual workers score somewhat higher than the higher controllers,

${ }^{20}$ There are considerable cross-national differences in the variation of individual characteristics as well as in the mean score of the dependent variables. Consequently, estimated parameters of individual characteristics obtained by an analysis without country dummies are distorted. 
Table 3. Unstandardized and Standardized Regression Parameter Estimates of Dimensions of Nationalism and Ethnic Exclusionism on Individual Characteristics in Overall Sample $(N=23,000)$

\begin{tabular}{|c|c|c|c|c|c|}
\hline Characteristic & Chauvinism & Patriotism & $\begin{array}{l}\text { Exclusion: } \\
\text { immigrants }\end{array}$ & $\begin{array}{c}\text { Exclusion: } \\
\text { political } \\
\text { refugees }\end{array}$ & $\begin{array}{c}\text { Exclusion } \\
\text { ingroup } \\
\text { membersh }\end{array}$ \\
\hline \multicolumn{6}{|l|}{ Unstandardized estimates } \\
\hline \multicolumn{6}{|l|}{ Education } \\
\hline Lower & $.42 * *$ & $.05 * *$ & $.33 * *$ & $.42 * *$ & $.25 * *$ \\
\hline Incomplete secondary & $.25 * *$ & .01 & $.25^{* *}$ & $.30 * *$ & $.17 * *$ \\
\hline Complete secondary & $.13 * *$ & .00 & $.14 * *$ & $.14 * *$ & $.07 * *$ \\
\hline Higher & Ref & Ref & Ref & Ref & Ref \\
\hline \multicolumn{6}{|l|}{ Social position } \\
\hline Higher controllers & Ref & Ref & Ref & Ref & Ref \\
\hline Lower controllers & -.01 & .02 & .03 & -.01 & -.00 \\
\hline Routine non-manual & .05 & .02 & $.12 * *$ & .06 & $.05 *$ \\
\hline Self-employed & $.08 * *$ & .00 & $.18^{* *}$ & $.12 * *$ & $.06^{*}$ \\
\hline Supervisors, skilled manual & $.09 * *$ & .01 & $.15^{* *}$ & $.14 * *$ & $.06^{*}$ \\
\hline Semi-unskilled manual & $.14 * *$ & -.01 & $.12 * *$ & .06 & $.11 * *$ \\
\hline Unemployed & $.06 *$ & -.03 & $.13 * *$ & .08 & $.10 * *$ \\
\hline Student, vocational training & $-.11 * *$ & .02 & -.04 & $-.14 * *$ & -.02 \\
\hline Retired & $.12 * *$ & .02 & $.13 * *$ & .06 & $.06^{* *}$ \\
\hline Housekeepers & $.09 * *$ & .02 & $.15^{* *}$ & $.12 * *$ & $.08 * *$ \\
\hline Not classifiable & $.06 *$ & -.01 & $.14^{* * *}$ & .07 & $.05^{*}$ \\
\hline Family income & $-.03 * *$ & $.01 *$ & $-.02 * *$ & $-.03 * *$ & $-.01 *$ \\
\hline Sex (male) & $.03 *$ & $.03 * *$ & $-.03 *$ & .01 & -.01 \\
\hline \multicolumn{6}{|l|}{ Age } \\
\hline $18-21$ & $-.29 * *$ & $-.13 * *$ & .00 & $.16^{* *}$ & $-.23 * *$ \\
\hline $22-26$ & $-.32 * *$ & $-.15 * *$ & -.03 & $.11^{*}$ & $-.22 * *$ \\
\hline $27-31$ & $-.31 * *$ & $-.16^{* *}$ & -.02 & .05 & $-.23 * *$ \\
\hline $32-36$ & $-.31 * *$ & $-.15 * *$ & -.01 & .05 & $-.24 * *$ \\
\hline $37-41$ & $-.26 * *$ & $-.14 * *$ & -.00 & .05 & $-.20 * *$ \\
\hline $42-46$ & $-.23 * *$ & $-.12 * *$ & -.01 & .04 & $-.22 * *$ \\
\hline $47-51$ & $-.21 * *$ & $-.13 * *$ & -.03 & -.00 & $-.19 * *$ \\
\hline $52-56$ & $-.12 * *$ & $-.10 * *$ & .02 & .03 & $-.14 * *$ \\
\hline $57-61$ & -.06 & $-.11 * *$ & .04 & .08 & $-.07 * *$ \\
\hline $62-66$ & $-.08 * *$ & $-.10 * *$ & .04 & .07 & $-.07 * *$ \\
\hline $67-71$ & -.02 & -.04 & .01 & -.08 & -.03 \\
\hline $72-75$ & Ref & Ref & Ref & Ref & Ref \\
\hline \multicolumn{6}{|l|}{ Religious denomination } \\
\hline Catholic & $.12 * *$ & $.03 *$ & $.11 * *$ & $.12 * *$ & $.15^{* *}$ \\
\hline Orthodox & .02 & .03 & -.01 & -.05 & -.03 \\
\hline Protestant & $.10^{* *}$ & $.05 *$ & $.15^{* *}$ & $.09 * *$ & $.15^{* *}$ \\
\hline Other & .03 & .00 & $.07 * *$ & -.03 & .03 \\
\hline No religion & Ref & Ref & Ref & Ref & Ref \\
\hline \multicolumn{6}{|l|}{ Church attendance } \\
\hline$\geq$ Nearly once a week & .03 & $.08 * *$ & $-.16^{* *}$ & $-.13 * *$ & -.00 \\
\hline$\geq$ Once a month & $.06 * *$ & $.07 * *$ & $-.15^{* *}$ & $-.09 * *$ & -.00 \\
\hline Less than once a month & $.04 * *$ & $.06 * *$ & $-.08 * *$ & -.01 & -.01 \\
\hline Never & Ref & Ref & Ref & Ref & Ref \\
\hline
\end{tabular}


Table 3. (cont.)

\begin{tabular}{lccccc}
\hline Characteristic & Chauvinism & Patriotism & $\begin{array}{c}\text { Exclusion: } \\
\text { immigrants }\end{array}$ & $\begin{array}{c}\text { Exclusion: } \\
\text { political } \\
\text { refugees }\end{array}$ & $\begin{array}{c}\text { Exclusion: } \\
\text { ingroup } \\
\text { membership }\end{array}$ \\
\hline Intercept & $3.38^{* *}$ & $2.68^{* *}$ & $3.63^{* *}$ & $2.78^{* *}$ & $3.01^{* *}$ \\
Adj. $R^{2}$ & .209 & .308 & .167 & .189 & .113 \\
\multicolumn{5}{c}{} & \multicolumn{4}{c}{} & & \\
Standardized estimates, applying composite variables for categorical variables & \\
Education & $.19^{* *}$ & $.03^{* *}$ & $.13^{* *}$ & $.13^{* *}$ & $.14^{* *}$ \\
Social position & $.08^{* *}$ & $.02^{* *}$ & $.06^{* *}$ & $.05^{* *}$ & $.06^{* *}$ \\
Family income & $-.03^{* *}$ & $.01^{*}$ & $-.02^{* *}$ & $-.03^{* *}$ & $-.01^{*}$ \\
Sex & $.02^{*}$ & $.02^{* *}$ & $-.02^{* *}$ & .00 & -.01 \\
Age & $.14^{* *}$ & $.05^{* *}$ & $.02^{* *}$ & $.04^{* *}$ & $.11^{* *}$ \\
Religious denomination & $.06^{* *}$ & $.03^{* *}$ & $.06^{* *}$ & $.05^{* *}$ & $.11^{* *}$ \\
Church attendance & $.03^{* *}$ & $.05^{* *}$ & $.06^{* *}$ & $.04^{* *}$ & .00 \\
\hline
\end{tabular}

Note. The effects of individual characteristics are controlled for the overall means of the 23 samples by including 22 dummy variables for the samples (parameter estimates not displayed). Ref $=$ reference category. For the standardized estimates, composite variables for education, social position, age, religious denomination, and church attendance were created using the unstandardized regression parameter estimates for the dummy variables as weights.

$* p<.05, * * p<.01$.

but the difference is only significant for two dimensions of ethnic exclusionism. With regard to social categories outside the labor force, we find that chauvinism is lower among students but higher among retired persons and people working in the household. For ethnic exclusionism we find the same pattern, although not all differences from the reference category are significant.

Controlled for educational level and social position, the effect of family income is rather small. The higher the income, the lower the degree of chauvinism and ethnic exclusionism. This finding is again in accordance with the notions of realistic group conflict theory. Patriotism, on the other hand, is slightly positively related to income level.

Next, we consider the effects of the control variables sex, age, religious denomination, and church attendance. Differences between the sexes are small: Males display more chauvinism and patriotism but are less exclusionistic toward immigrants. Regarding age differences, the results are only partly in accordance with previous findings that indicate that the young are less nationalistic and less prejudiced (Eisinga \& Scheepers, 1989; Smith, 1985). Indeed, younger birth cohorts appear less chauvinistic and patriotic than older birth cohorts. The relationship is almost linear. In addition, the young are less negative toward ethnic outgroups regarding exclusion from ingroup membership. However, regarding exclusion of immigrants and political refugees, the young are not more tolerant than the old; it appears that the youngest respondents are more in favor of exclusion of political refugees than are the older cohorts. This may indicate decreasing support for the admission of political refugees in the near future. 
In general, religious respondents are more nationalistic and exclusionistic than non-religious respondents. Orthodox religious respondents-predominantly inhabitants of Bulgaria, the Slovak Republic, and Russia-do not deviate from non-religious respondents. The results for church attendance are mixed and somewhat puzzling. Whereas churchgoers are more nationalistic than nonchurchgoers, they appear to be relatively less exclusionistic toward immigrants and political refugees.

Our results indicate that educational attainment is strongly related to chauvinism and ethnic exclusionism, even after controlling for a number of individual characteristics interrelated with educational level, such as social class position, income, age, religious affiliation, and church attendance. To investigate the relative importance of educational attainment for the explanation of our dependent variables, we created composite variables for all categorical variables. A composite or compound variable for each categorical variable was created by using the estimated unstandardized regression coefficients for the dummified categories, as displayed in Table 3, as weights (Eisinga, Scheepers, \& van Snippenburg, 1991). Next, we conducted a second regression analysis in which each categorical variable was replaced by its composite variable. The standardized regression coefficient for the composite variable (also referred to as the Sheaf coefficient) reveals the overall effect of the categorical variable, and can be compared with the effect of non-categorical variables such as income. The standardized regression coefficients are displayed in Table $3 .{ }^{21}$ This table shows that, controlled for all other individual variables, education has the strongest overall effect on chauvinism and ethnic exclusionism. Compared to education, the effects of social position and income are considerably smaller. In sum, in multivariate analyses, education turns out to be the most important indicator for the explanation of individual differences in chauvinism and ethnic exclusionism. Patriotism, however, is hardly affected by educational attainment and is more strongly related to age and church attendance.

Next, we investigated whether the effect of education varies systematically across countries according to the length of liberal-democratic regime history or the degree of religious heterogeneity of the country. For a formal test of the varying effects of education, we computed interaction variables between education and liberal democratic tradition, and between education and religious heterogeneity. For convenience and clarity, educational attainment was treated as an interval variable in these analyses.

First, we tested whether the effect of education depends on the length of time a country has had a liberal-democratic regime form. Table 4 summarizes the

${ }^{21}$ The Sheaf coefficients for education, social position, age, religious denomination, and church attendance are displayed along with the standardized coefficient for sex and the unstandardized coefficient for income, because the latter variable was standardized in advance within each country. Note that the positive sign of the Sheaf coefficients is a technical artifice (Eisinga et al., 1991) and is therefore not related to the sign of the relationship between independent and dependent variable. 
Table 4. Unstandardized Regression Parameter Estimates of Dimensions of Nationalism and Ethnic Exclusionism on Educational Attainment and Interaction Between Educational Attainment and Length of Democratic Tradition $(N=23,000)$

\begin{tabular}{lccccc}
\hline Characteristic & Chauvinism & Patriotism & $\begin{array}{c}\text { Exclusion: } \\
\text { immigrants }\end{array}$ & $\begin{array}{c}\text { Exclusion: } \\
\text { political } \\
\text { refugees }\end{array}$ & $\begin{array}{c}\text { Exclusion: } \\
\text { ingroup } \\
\text { membership }\end{array}$ \\
\hline $\begin{array}{c}\text { Education (in prolonged } \\
\text { democracies) }\end{array}$ & $-.137^{* *}$ & -.008 & $-.145^{* *}$ & $-.167^{* *}$ & $-.104^{* * *}$ \\
$\begin{array}{c}\text { Education } \times \text { interrupted } \\
\text { democracies }\end{array}$ & $-.032^{* *}$ & $-.043^{* *}$ & .008 & -.022 & -.011 \\
$\begin{array}{c}\text { Education } \times \text { most recent } \\
\text { democracies }\end{array}$ & .019 & -.001 & $.086^{* *}$ & $.072^{* *}$ & $.055^{* *}$ \\
\hline
\end{tabular}

Note. The main and interaction effects of educational attainment are controlled for all individual characteristics as displayed in Table 3 as well as for the overall means of the 23 samples by including 22 dummy variables for the samples (parameter estimates not displayed).

$* p<.05, * * p<.01$.

results, presenting only the parameter estimates for educational attainment. Note that these are multivariate parameter estimates, controlled for all other individual characteristics (social position, family income, sex, age, religious denomination, and church attendance). The first row in Table 4 displays the main effect of education, which indicates the educational effect in prolonged democracies. This serves as the reference point for the interpretation of the interaction parameters. The next two rows display the parameter estimates of the two interaction variables, representing the difference in the effect of education in interrupted democracies or recently established democracies, respectively, as compared to the educational effect in prolonged democracies.

Let us first consider the effect of education on ethnic exclusionism. According to Hypothesis 1a, the effect of education is smaller in recently established democracies than in other countries. As can be seen in the third row of Table 4, the last three parameter estimates are significantly positive. This indicates that the negative effect of education on exclusionism is, indeed, significantly less strong in the most recently established democracies, compared to the educational effect in prolonged democracies: People with higher education are less exclusionistic than those with lower education, but the difference between these groups is smaller in the recently established democracies in Eastern Europe and Russia.

We furthermore assumed that the difference between educational groups would be stronger in prolonged democracies as compared to less prolonged or interrupted democracies. However, regarding the effect of education on ethnic exclusionism, the parameter estimates in the second row of Table 4 indicate that the educational effect in interrupted democracies does not significantly deviate from the educational effect in prolonged democracies. This contradicts our Hypothesis 1b. Furthermore, a comparison of parameter estimates in Table 4 
reveals that the effect of education on ethnic exclusionism in interrupted democracies is stronger than in recently established democracies. A replication of the analysis, with the educational effect in recently established democracies as reference, showed that this difference is indeed significant.

In sum, the effect of education on ethnic exclusionism is significantly less strong in recently established democracies than in either prolonged democracies or interrupted democracies, confirming Hypothesis 1a. However, the educational effect in prolonged democracies does not significantly deviate from the educational effect in interrupted democracies, refuting Hypothesis $1 b$.

Let us now turn to the effect of education on chauvinism and patriotism. As shown in Table 4, there is no significant difference in the effect of education in recently established democracies as compared to the effect of education in prolonged democracies. Furthermore, the parameters in the second row of Table 4 indicate that the negative effect of education in interrupted democracies iscontrary to our expectation-significantly stronger than in prolonged democracies. These findings refute Hypotheses $1 \mathrm{a}$ and $1 \mathrm{~b}$ regarding the varying effect of education on nationalism.

To formally test the differential effects of education in prolonged, interrupted, and newly established democracies, we had treated education as an interval variable for matters of convenience and clarity. Now that we have established that the educational effect does vary to some extent between these types of countries, we present the parameter estimates for all educational categories. Table 5 shows the results of separate multivariate regression analyses for prolonged, interrupted, and recently established democracies. Note once again that the parameter estimates for educational attainment are controlled for all other individual characteristics.

As already established in a formal manner, we see in Table 5 that, regarding ethnic exclusionism, the differences between educational groups are considerably smaller in recently established democracies compared to prolonged or interrupted democracies. The differences in educational effects between the latter two types of countries are minor. Regarding chauvinism and patriotism, we find relatively small differences in the effect of education in the three types of countries.

Next, we tested whether the effect of education varies according to the degree of religious heterogeneity. The results are summarized in Table 6, in which the parameter estimates of educational attainment (as an interval variable) and the interaction between educational attainment and degree of religious heterogeneity of a country are displayed. Note once again that these are multivariate parameter estimates, controlled for all other individual characteristics as displayed in Table 3.

According to Hypothesis 2, the effect of education on nationalism and ethnic exclusionism is stronger in more heterogeneous societies. However, as shown in the second row of Table 6, for four of the dependent variables, we found no significant interaction between the size of the (linear) educational effect and the degree of religious heterogeneity of a country. This refutes our hypothesis. Only 
Table 5. Unstandardized Regression Parameter Estimates of the Effect of Educational Attainment on Dimensions of Nationalism and Ethnic Exclusionism in Three Types of Countries, Grouped by Length of Liberal-Democratic Regime History

\begin{tabular}{lcccc}
\hline Education & $\begin{array}{c}\text { All countries } \\
(n=23,000)\end{array}$ & $\begin{array}{c}\text { Prolonged } \\
\text { democracies } \\
(n=9,000)\end{array}$ & $\begin{array}{c}\text { Interrupted } \\
\text { democracies }\end{array}$ & $\begin{array}{c}\text { Recently } \\
\text { established } \\
(n=5,000)\end{array}$ \\
& & $(n=9,000)$ \\
\hline
\end{tabular}

\section{Chauvinism}

Lower

Incomplete secondary

Complete secondary

Higher

\section{Patriotism}

Lower

Incomplete secondary

Complete secondary

Higher

\section{Exclusion of immigrants}

Lower

Incomplete secondary

Complete secondary

Higher

\section{Exclusion of political refugees}

Lower

Incomplete secondary

Complete secondary

Higher

Exclusion from ingroup membership

Lower

Incomplete secondary

Complete secondary

Higher
$.42 * *$

$.25 * *$

$.13 * *$

Ref

$.05^{* * *}$

.01

.00

Ref

$.33^{* *}$

$.25 * *$

$.14 * *$

Ref

$.42 * *$

.30 **

$.14 * *$

Ref

$.25 * *$
$.17^{* *}$
$.07 * *$
Ref

$.44 * *$
$.30^{* *}$
$.14^{* *}$
$\operatorname{Ref}$

$.43^{* *}$

$.25 * *$

$.11^{* *}$

Ref

$.37 * *$

$.23 * *$

$.14 * *$

Ref

08 **

.02

$.05^{*}$
.02
.02
Ref

.02

$-.00$

.03

$-.02$

Ref

Ref

$.37 * *$

$.20 * *$

.32 **

.12 **

.10 **

Ref

$.06 *$

Ref

Ref

Note. The parameter estimates are controlled for other individual characteristics (i.e., social position, family income, sex, age, religious denomination, and church attendance) as well as for the overall means of the samples by including $k-1$ dummy variables for the $k$ samples (parameter estimates not displayed). Ref $=$ reference category.

$* p<.05, * * p<.01$.

with regard to patriotism do we find a minor significant $(p=.049)$ interaction effect between education and religious heterogeneity, but the sign of this effect is contrary to our expectation: The negative effect of education is slightly lower in more heterogeneous societies. In short, we found no support for our hypothesis regarding the degree of cultural pluralism. 
Table 6. Unstandardized Regression Parameter Estimates of Dimensions of Nationalism and Ethnic Exclusionism on Educational Attainment and Interaction Between Educational Attainment and Religious Heterogeneity $(N=23,000)$

\begin{tabular}{lccccc}
\hline Characteristic & Chauvinism & Patriotism & $\begin{array}{c}\text { Exclusion: } \\
\text { immigrants }\end{array}$ & $\begin{array}{c}\text { Exclusion: } \\
\text { political } \\
\text { refugees }\end{array}$ & $\begin{array}{c}\text { Exclusion: } \\
\text { ingroup } \\
\text { membership }\end{array}$ \\
\hline Education & $-.141^{* *}$ & $-.035^{* *}$ & $-.095^{* *}$ & $-.133^{* *}$ & $-.071^{* *}$ \\
$\begin{array}{l}\text { Education } \times \text { religious } \\
\text { heterogeneity }\end{array}$ & .007 & $.031^{*}$ & -.027 & -.019 & -.027 \\
\hline
\end{tabular}

Note. The main and interaction effects of educational attainment are controlled for all individual characteristics as displayed in Table 3 as well as for the overall means of the 23 samples by including 22 dummy variables for the samples (parameter estimates not displayed).

$* p<.05, * * p<.01$.

\section{Discussion and Conclusions}

Our results indicate that the effect of education on ethnic exclusionism is, in accordance with our hypothesis, significantly smaller in recently established democracies as compared to prolonged or interrupted democracies. However, contrary to our expectation, the effect of education on ethnic exclusionism in interrupted democracies does not deviate from the educational effect in prolonged democracies. Regarding the effect of education on nationalism, our hypotheses were also not confirmed: The effect of education was found to be a bit stronger in interrupted democracies relative to prolonged democracies. Furthermore, there was no significant difference between prolonged democracies and recently established democracies regarding the effect of education on nationalism. Finally, we found no support for the hypothesis that the effect of education is stronger in societies with more religious heterogeneity.

In sum, the hypotheses derived from socialization theory were only partly supported. The effect of education does indeed depend on the liberal-democratic tradition of a country, insofar as we found that the educational effect on ethnic exclusionism is smaller in recently established democracies. This supports the notion that the values that are transmitted by the educational system reflect the extent to which a country has had a liberal-democratic tradition: In established democracies, the educational institutions promulgate democratic values and ideals. Consequently, the difference in ethnic exclusionistic attitudes between higher- and lower-educated people is stronger in established democracies.

According to Weil, there is a time lag between a change in political regime form and the ability of the educational system to socialize students into the new official political culture. Consequently, we assumed that the effect of education would be stronger in prolonged democracies as compared to countries where the liberal-democratic tradition had been interrupted in the 1940s (or, as in the case of Spain, even after 1945). However, our finding that the effect of education on 
ethnic exclusionism in interrupted democracies (i.e., West Germany, Austria, Italy, Spain, and Japan) is not smaller than the effect of education in more prolonged democracies suggests that, in 1995, the populations of interrupted democracies have been socialized to democratic values to the same extent as the populations of prolonged democracies.

When we compare the effect of education in prolonged and recently established democracies, our results indicate that in countries with a short democratic history, the effect of education on ethnic exclusionism is smaller, but there is no difference in the effect of education on nationalism. A possible interpretation of this dissimilar result is the proposition that educational institutions in countries with a longstanding democratic history transmit and promulgate the ideals of democracy and tolerance, but that the focus is more on the deprecation of outgroup hostility than on the deprecation of ingroup favoritism.

Finally, our results indicate that the effect of education does not depend on the degree of cultural pluralism within a country. Our hypothesis that the effect of education would be stronger in plural societies was based on political theories of conflict resolution in plural societies. According to Lijphart (1977), in a plural society political elites must take the lead in promoting peaceful accommodation among the different population segments. Because, according to socialization theory, the values and norms transmitted by the educational system reflect the political culture of a country, one would expect that in a heterogeneous society, educational institutions are more likely to instill tolerant attitudes (Weil, 1985). An alternative test of the notion of conflict resolution in societies with varying degrees of cultural pluralism would be to focus not on public opinion, as we have done, but instead on the attitudes of the political elites in these countries.

\section{APPENDIX A: National Characteristics}

\begin{tabular}{llll} 
Country & $\begin{array}{c}\text { Liberal-democratic } \\
\text { tradition }\end{array}$ & \multicolumn{2}{c}{$\begin{array}{c}\text { Religious } \\
\text { heterogeneity }\end{array}$} \\
\hline Australia & Long & High & .88 \\
Austria & Interrupted & Moderate & .43 \\
Bulgaria & Short & Moderate & .40 \\
Canada & Long & High & .78 \\
Czech Republic & Short & Moderate & .63 \\
Germany (east) & Short & Moderate & .64 \\
Germany (west) & Interrupted & High & .79 \\
Great Britain & Long & High & .76 \\
Hungary & Short & Moderate \\
Ireland & Long & Low & .57 \\
Italy & Interrupted & Low & .15 \\
Japan & Interrupted & Moderate & .14 \\
Latvia & Short & High & .59 \\
Netherlands & Long & Moderate & .86 \\
New Zealand & Long & High & .66 \\
Norway & Long & Low & .87 \\
& & & .27
\end{tabular}


APPENDIX A: (cont.)

\begin{tabular}{llll}
\hline Poland & Short & Low & .27 \\
Russia & Short & Moderate & .65 \\
Slovak Republic & Short & Moderate & .61 \\
Slovenia & Short & Moderate & .43 \\
Spain & Interrupted & Low & .18 \\
Sweden & Long & Moderate & .57 \\
United States & Long & High & .94 \\
\hline
\end{tabular}

\section{APPENDIX B: Selection of Respondents From Ethnic Majority Group}

In most of the samples, the racial/ethnic group of respondents was measured by one of the following two strategies: (1) A list of the major ethnic groups of the country was constructed and respondents were asked to place themselves on this list; (2) respondents were asked, "From what countries or part of the world did your ancestors come?" Some ISSP members, however, used their own standard variable as included in the demographic part of their national questionnaire. The following table summarizes the data on the national samples.

\begin{tabular}{lrlrr} 
Country & $\begin{array}{c}\text { Sample } \\
\text { size }\end{array}$ & $\begin{array}{c}\text { Ethnic majority group } \\
\text { "Label" }\end{array}$ & $(\%)$ & $\begin{array}{r}\text { Final } \\
\text { sample size }\end{array}$ \\
\hline Australia & 2,261 & Parents citizens of country & 72.5 & 1,640 \\
Austria & 939 & Austrian & 88.1 & 827 \\
Bulgaria & 1,037 & Bulgarian & 83.4 & 865 \\
Canada & 1,413 & West Europe & 1,151 \\
Czech Republic & 1,055 & Czech & 81.5 & 829 \\
Germany (west) & 1,214 & German & 78.6 & 1,111 \\
Germany (east) & 581 & German & 91.5 & 562 \\
Great Britain & 987 & White, British & 96.7 & 909 \\
Hungary & 939 & Hungarian & 92.1 & 925 \\
Ireland & 942 & Parents citizens of country & 98.5 & 902 \\
Italy & 1,094 & Parents citizens of country & 95.8 & 1,074 \\
Japan & 1,149 & Japanese & 98.2 & 1,133 \\
Latvia & 1,011 & Latvian & 98.6 & 598 \\
Netherlands & 1,952 & Dutch & $59.1^{\mathrm{d}}$ & 1,883 \\
New Zealand & 968 & Western industrial societies ${ }^{\mathrm{c}}$ & 96.5 & 74.4 \\
Norway & 1,428 & Norwegian & 95.6 & 1,365 \\
Poland & 1,518 & Polish & 97.0 & 1,473 \\
Russia & 1,552 & Russian & 83.0 & 1,288 \\
Slovak Republic & 1,362 & Slovakian & 87.4 & 1,191 \\
Slovenia & 1,021 & Slovenian & 91.9 & 938 \\
Spain & 1,161 & Parents citizens of country & 98.6 & 1,145 \\
Sweden & 1,283 & Swedish & 92.6 & 1,188 \\
U.S.A. & 1,294 & White & 80.4 & 1,041 \\
Total & 28,161 & Ethnic majority group & 88.0 & 24,778 \\
\hline
\end{tabular}

${ }^{a}$ Age limits differed between the original samples. For comparability, only respondents between 18 and 75 years of age are included in the analyses. 
because the variable "racial/ethnic group" was not available in this sample, respondents were selected if both parents were citizens of the specific country at the time the respondent was born. ${ }^{\mathrm{c}}$ Multiple categories.

${ }^{\mathrm{d}} 30.2 \%$ of the respondents in the Latvian sample are Russians.

${ }^{\text {e}}$ For the U.S. sample, the number of missings on the variable "racial/ethnic group" is very high (21.2\%). Fortunately, the original U.S. data set—which consists of a much larger set of items than those available in the ISSP 1995 data set-contains an additional variable "racial-ethnic group of respondent" with the categories "black / white / other." We matched this item to the ISSP 1995 data set and applied this item to select respondents who defined themselves as "whites."

\section{ACKNOWLEDGMENTS}

This research was supported by the Netherlands Organization for Scientific Research (NWO) and is part of a larger research project by Dutch sociologists and social psychologists entitled "Cross-National Comparisons of National Identifications and Exclusionistic Reactions." Correspondence concerning this article should be sent to Marcel Coenders, Department of Research Methodology/ICS, University of Nijmegen, P.O. Box 9104, 6500 HE Nijmegen, Netherlands. E-mail: m.coenders@maw.kun.nl

\section{REFERENCES}

Adorno, T. W., Frenkel-Brunswik, E., Levinson, D. J., \& Sanford, R. N. (1950). The authoritarian personality. New York: Harper.

Agresti, A., \& Agresti, B. F. (1977). Statistical analysis of qualitative variation. In K. F. Schuessler (Ed.), Sociological methodology 1978 (pp. 204-237). San Francisco: Jossey-Bass.

Bar-Tal, D., \& Staub, E. (Eds.). (1997). Patriotism in the lives of individuals and nations. Chicago: Nelson-Hall.

Bielby, W. T. (1986). Arbitrary metrics in multiple-indicator models of latent variables. Sociological Methods \& Research, 15, 3-23.

Billiet, J., Carton, A., \& Huys, R. (1990). Onbekend of onbemind? Een sociologisch onderzoek naar de houding van de belgen tegenover migranten. Leuven, Belgium: Sociologisch Onderzoeksinstituut.

Blalock, H. M. (1967). Toward a theory of minority-group relations. New York: Wiley.

Blank, T., \& Schmidt, P. (1993). Verletzte oder verletzende Nation? Empirische Befunde zum Stolz auf Deutschland. Journal für Sozialforschung, 33, 391-415.

Blumer, H. (1958). Race prejudice as a sense of group position. Pacific Sociological Review, 1(1), 3-7.

Bobo, L. (1988). Group conflict, prejudice, and the paradox of contemporary racial attitudes. In P. A. Katz \& D. A. Taylor (Eds.), Eliminating racism. Profiles in controversy (pp. 85-114). New York: Plenum.

Bobo, L., \& Licari, F. C. (1989). Education and political tolerance. Testing the effects of cognitive sophistication and target group affect. Public Opinion Quarterly, 53, 285-308.

Bollen, K. A. (1989). Structural equations with latent variables. New York: Wiley.

Browne, M. W., \& Cudeck, R. (1992). Alternative ways of assessing model fit. Sociological Methods \& Research, 21, 230-258. 
Coenders, M., \& Scheepers, P. (1998). Support for ethnic discrimination in the Netherlands 1979-1993: Effects of period, cohort, and individual characteristics. European Sociological Review, 14, 405-422.

Coenders, M., \& Scheepers, P. (1999). Een internationale vergelijking van nationalisme en etnisch exclusionisme. In W. A. R. Shadid \& P. S. Koningsveld (Eds.), Beeldvorming en Interculturele Communicatie (pp. 15-40). Tilburg, Netherlands: Tilburg University Press.

Coser, L. A. (1956). The functions of social conflict. Glencoe, IL: Free Press.

de Witte, H. (1999). "Everyday" racism in Belgium: An overview of the research and an interpretation of its link with education. In L. Hagendoorn \& S. Nekuee (Eds.), Education and racism: A cross-national inventory of positive effects of education on ethnic tolerance (pp. 47-74). Utrecht, Netherlands: ERCOMER/Utrecht University.

Eisinga, R., \& Scheepers, P. (1989). Etnocentrisme in Nederland. Theoretische en empirische modellen. Nijmegen, Netherlands: ITS.

Eisinga, R., Scheepers, P., \& van Snippenburg, L. (1991). The standardized effect of a compound of dummy variables or polynomial terms. Quality \& Quantity, 25, 103-114.

Erikson, R., Goldthorpe, J. H., \& Portocarero, L. (1979). International class mobility in three Western European countries. British Journal of Sociology, 30, 415-441.

Fuchs, D., Gerhards, J., \& Roller, E. (1993). Wir und die Anderen. Ethnozentrismus in den zwölf Ländern der europäischen Gemeinschaft. Kölner Zeitschrift für Soziologie und Sozialpsychologie, 45, 238-253.

Gabennesch, H. (1972). Authoritarianism as world view. American Journal of Sociology, 77, 857-875.

Ganzeboom, H. B. G., Luijkx, R., \& Treiman, D. J. (1989). Intergenerational class mobility in comparative perspective. Research in Social Stratification and Mobility, 8, 3-84.

Ganzeboom, H. B. G., \& Treiman, D. J. (1996). Internationally comparable measures of occupational status for the 1988 International Standard Classification of Occupations. Social Science Research, 25, 201-239.

Greeley, A. M., \& Sheatsley, P. B. (1971). Attitudes toward racial integration. Scientific American, 225(6), 13-19.

Hyman, H. H., \& Sheatsley, P. B. (1956). Attitudes toward desegregation. Scientific American, 195(6), 35-39.

Hyman, H. H., \& Sheatsley, P. B. (1964). Attitudes toward desegregation. Scientific American, 211(1), $16-23$.

Hyman, H. H., \& Wright, C. R. (1979). Education's lasting influence on values. Chicago: The University of Chicago Press.

Hyman, H. H., Wright, C. R., \& Reed, J. S. (1975). The enduring effects of education. Chicago: University of Chicago Press.

International Labor Office (1969). International standard classification of occupations: ISCO68. Geneva: Author.

International Labor Office (1990). International standard classification of occupations: ISCO88. Geneva: Author.

Jackman, M. (1973). Education and prejudice or education and response-set? American Sociological Review, 38, 327-339.

Jackman, M. (1978). General and applied tolerance: Does education increase commitment to racial integration? American Journal of Political Science, 22, 302-324.

Jackman, M., \& Muha, M. (1984). Education and intergroup attitudes. Moral enlightenment, superficial democratic commitment, or ideological refinement? American Sociological Review, 49, 751-769.

Jöreskog, K. G., \& Sörbom, D. (1993a). LISREL 8: Structural equation modeling with the SIMPLIS command language. Chicago: Scientific Software International. 
Jöreskog, K. G., \& Sörbom, D. (1993b). LISREL 8 user's reference guide. Chicago: Scientific Software International.

Kiehl, M., \& Werner, H. (1998). The labour market situation of EU and of third country nationals in the European Union. Labour market topics no. 32. Nürnberg, Germany: Institut für Arbeitsmarkt- und Berufsforschung der Bundesanstalt für Arbeit.

Kosterman, R., \& Feshbach, S. (1989). Toward a measure of patriotic and nationalistic attitudes. Political Psychology, 10, 257-274.

LeVine, R. A., \& Campbell, D. T. (1972). Ethnocentrism: Theories of conflict, ethnic attitudes, and group behavior. New York: Wiley.

Lijphart, A. (1977). Democracy in plural societies. A comparative exploration. New Haven, CT: Yale University Press.

Lipset, S. M. (1981). Political man. The social bases of politics (Expanded and updated ed.). Baltimore: Johns Hopkins University Press.

Martire, G., \& Clark, R. (1982). Anti-Semitism in the United States. A study of prejudice in the 1980s. New York: Praeger.

Olzak, S., \& Nagel, J. (1986). Competitive ethnic relations. Orlando, FL: Academic Press.

Roof, W. C. (1974). Religious orthodoxy and minority prejudice: Causal relationship or reflection of localistic world view. American Journal of Sociology, 80, 630-644.

Schatz, R., Staub, E. \& Lavine, H. (1999). On the varieties of national attachment: Blind versus constructive patriotism. Political Psychology, 20, 151-174.

Scheepers, P., Felling, A., \& Peters, J. (1990). Social conditions, authoritarianism and ethnocentrism: A theoretical model of the early Frankfurt School updated and tested. European Sociological Review, 6, 15-29.

Schönbach, P., Gollwitzer, P., Stiepel, G., \& Wagner, U. (1981). Education and intergroup attitudes. London: Academic Press.

Schuman, H., Steeh, C., Bobo, L., \& Krysan, M. (1997). Racial attitudes in America. Trends and interpretations (rev. ed.). Cambridge, MA: Harvard University Press.

Selznick, G. J., \& Steinberg, S. (1969). The tenacity of prejudice. Anti-Semitism in contemporary America. New York: Harper and Row.

Sherif, M., \& Sherif, C. W. (1979). Research on intergroup relations. In W. G. Austin \& S. Worchel (Eds.), The social psychology of intergroup relations (pp. 7-18). Monterey, CA: Brooks/Cole.

Smith, A. W. (1981). Racial tolerance as a function of group position. American Sociological Review, $46,558-573$.

Smith, A. W. (1985). Cohorts, education, and the evolution of tolerance. Social Science Research, 14, 205-225.

Staub, E. (1997). Blind versus constructive patriotism: Moving from embeddedness in the group to critical loyalty and action. In D. Bar-Tal \& E. Staub (Eds.), Patriotism in the lives of individuals and nations (pp. 213-228). Chicago: Nelson-Hall.

Stephan, W. G., \& Stephan, C. W. (1984). The role of ignorance in intergroup relations. In N. Miller \& M. B. Brewer (Eds.), Groups in contact: The psychology of desegregation (pp. 229-255). Orlando, FL: Academic Press.

Stouffer, S. A. (1955). Communism, conformity, and civil liberties. New York: Wiley.

Sumner, W. G. (1959). Folkways. New York: Dover. (Original work published 1906)

Tajfel, H. (1981). Human groups and social categories: Studies in social psychology. Cambridge: Cambridge University Press.

Tajfel, H. (1982). Social identity and intergroup relations. Cambridge: Cambridge University Press.

Taylor, D. G., Sheatsley, P. B., \& Greeley, A. M. (1978). Attitudes toward racial integration. Scientific American, 238(6), 30-37. 
Vogt, P. W. (1997). Tolerance and education. Learning to live with diversity and difference. Thousand Oaks, CA: Sage.

Wagner, U., \& Schönbach, P. (1984). Links between educational status and prejudice: Ethnic attitudes in West Germany. In N. Miller \& M. B. Brewer (Eds.), Groups in contact: The psychology of desegregation (pp. 29-52). Orlando, FL: Academic Press.

Wagner, U., \& Zick, A. (1995). The relation of formal education to ethnic prejudice: Its reliability, validity and explanation. European Journal of Social Psychology, 25, 41-56.

Walzer, S. (1994). The role of gender in determining abortion attitudes. Social Science Quarterly, 89, 963-966.

Weil, F. D. (1985). The variable effects of education on liberal attitudes: A comparative-historical analysis of anti-Semitism using public opinion survey data. American Sociological Review, 50, 458-474.

Wilcox, C. (1992). Race, religion and abortion attitudes. Sociological Analysis, 53, 97-105.

Williams, R., \& Thomson, E. (1986). Normalization issues in latent variable modeling. Sociological Methods \& Research, 15, 24-43.

Winkler, J. (1999). Explaining individual racial prejudice in contemporary Germany. In L. Hagendoorn \& S. Nekuee (Eds.), Education and racism: A cross-national inventory of positive effects of education on ethnic tolerance (pp. 93-136). Utrecht, Netherlands: ERCOMER/ Utrecht University.

Zentralarchiv für Empirische Sozialforschung (1998). Codebook ZA Study 2880: ISSP 1995 National Identity (2nd ed., May 1998). Köln: Author. 